\title{
The detailed net mass balance of the ice plain on Ice Stream B, Antarctica: a geographic information system approach
}

\author{
ROBERT BINDSCHADLER, \\ NASA/Goddard Space Flight Center, Code 971, Greenbelt, Maryland 20771, U.S.A. \\ PATRICIA L. VORNBERGER, \\ Hughes/STX Corporation, 4400 Forbes Boulevard, Lanham, Maryland 20706, U.S.A. \\ Sion ShabTaIE \\ Geophysics and Polar Research Center, University of Wisconsin-Madison, Madison, Wisconsin 53706, U.S.A.
}

\begin{abstract}
Field data of ice thickness, velocity and accumulation of the ice plain region of Ice Stream B, Antarctica, are organized into a geographic information system (GIS) and used to calculate the spatial pattern of net mass balance. Overall, the ice plain is thickening at a rate of $0.13 \pm 0.05 \mathrm{~m} \mathrm{a}^{-1}$. Large uncertainties of the high-resolution calculations are reduced by spatial averaging, revealing a number of areas significantly out of balance. Ice in the broad diverging flow field is mostly thinning but a thinner region of the ice plain which includes ice raft " $a$ " is thickening. Thickening is also indicated farther downstream on the ice plain, matching the thickening already calculated to be occurring upstream of Crary Ice Rise. The patterns of net mass balance for the two major tributaries of Ice Stream $\mathrm{B}$ are asymmetric, demonstrating a real difference in the current dynamics of these two tributaries.
\end{abstract}

\section{INTRODUCTION}

The net mass balance of an ice mass defines the rate at which the volume of that mass is changing. It is the sum of all mass inputs minus the sum of all mass removals. As such, it is the fundamental measure of the "state of health" for either a local region or an entire glacier or ice sheet. The pattern of local net mass-balance measurements distributed throughout an area helps the glaciologist understand the current dynamics of that region and benefits field operations by identifying those areas undergoing change.

The usual limitation to local net mass-balance calculations is that both the total mass input and total mass removal are large compared to the difference between these two numbers. Thus, the uncertainty in such a calculation is very sensitive to the accuracy of the data, especially those parameters that exhibit large spatial variations. Typically, to minimize errors associated with spatial gradients, the locations of the measurements dictate the boundaries of regions over which net mass balance is calculated. This can lead to irregularly shaped regions or regions poorly arranged to exhibit a meaningful spatial pattern of net mass balance.

Recent innovations in measurement techniques are increasing the ability to collect densely spaced data for calculation of detailed patterns of net mass balance. The
Global Positioning System (GPS) allows the rapid and accurate positioning of receivers. With kinematic GPS techniques, aircraft equipped with sounding radars can fly dense grid networks with precise knowledge of position, eliminating errors in the ice-thickness data due to the combination of spatial thickness gradients and location uncertainties. Also, GPS equipment will enable more surface-velocity measurements to be collected per unit time than has been possible before. Just as significant is the ability to obtain accurate surface velocities from sequential satellite imagery thus allowing velocity fields as dense as the surface features themselves (Bindschadler and Scambos, 1991). Finally, measurements of passive microwave emissions and surface temperature from satellite sensors may eventually provide a means of calculating the spatial pattern of snow accumulation using only a few surface-truth tiepoints (Zwally, 1977; paper in preparation by H.J. Zwally and others).

The concept of a geographical information system (GIS) furnishes a framework within which these data fields can be conveniently combined to calculate net mass balance. In this paper, we apply the GIS concept to the calculation of a detailed pattern of net mass balance. The application is not ideal because the original data were not collected with this technique in mind and do not use the satellite-based techniques described above. Nevertheless, the demonstration of this approach illustrates consider- 
able advantages over established methods and justifies the collection of data sets more appropriate to this method in other ice-covered regions. Most importantly, the calculations reveal not only that there are significant changes in ice thickness occurring on the ice plain of Ice Stream B but that the pattern of thickening and thinning exhibits a major asymmetry between the two tributaries of Ice Stream B, denoting real differences in the present dynamics of these two tributaries.

\section{ICE PLAIN OF ICE STREAM B}

Ice Stream B is located in West Antarctica and is a major tributary of the Ross Ice Shelf (Fig. 1). It comprises two major tributaries, designated $\mathrm{B} 1$ and $\mathrm{B} 2$, which join almost $200 \mathrm{~km}$ upstream of station DNB. The boundary between these two tributaries can be identified on aerial photographs and radar-sounding data, and persists along the entire ice stream downstream of the B1/B2 confluence.

Ice Stream B has been the focus of a great deal of study, most since 1983 by the Siple Coast Project (Whillans and Alley, 1991; see other papers in this issue). Overall, the ice stream contributes $30.0 \mathrm{~km}^{3} \mathrm{a}^{-1}$ to the Ross Ice Shelf and has been calculated to be in negative net mass balance by about $40 \%$ (Whillans and Bindschadler, 1988). Shabtaie and others (1988) have shown that the pattern of net mass balance along this ice stream supports the hypothesis that the excess mass discharged by this ice stream comes from its upstream limit and diffuses rapidly along the length of the ice stream as it flows seaward.

In the mouth of the ice stream lies a very slightly grounded region called the ice plain (Bindschadler and others, 1987). It extends from the cross-stream profile at station DNB to the grounding line (see Fig. 1). Bindschadler (1993) has given a comprehensive review of the dynamics of the ice plain, including measurements as early as during the International Geophysical Year (IGY) in 1957-58. The ice plain is known to be undergoing change. Stephenson and Bindschadler (1988) determined that, at all three points in this region where ice-flow velocities were measured in the mid-1970s, the velocities by the mid-1980s had decreased an average of $20 \%$. Also, by using the traditional method of net massbalance calculation, Bindschadler and others (1989) calculated that the average thickening rate just upstream of Crary Ice Rise was $0.76 \mathrm{~m} \mathrm{a}^{-1}$ and that the ice rise must therefore be migrating upstream.

Within the ice plain is a feature called ice raft " $a$ ".

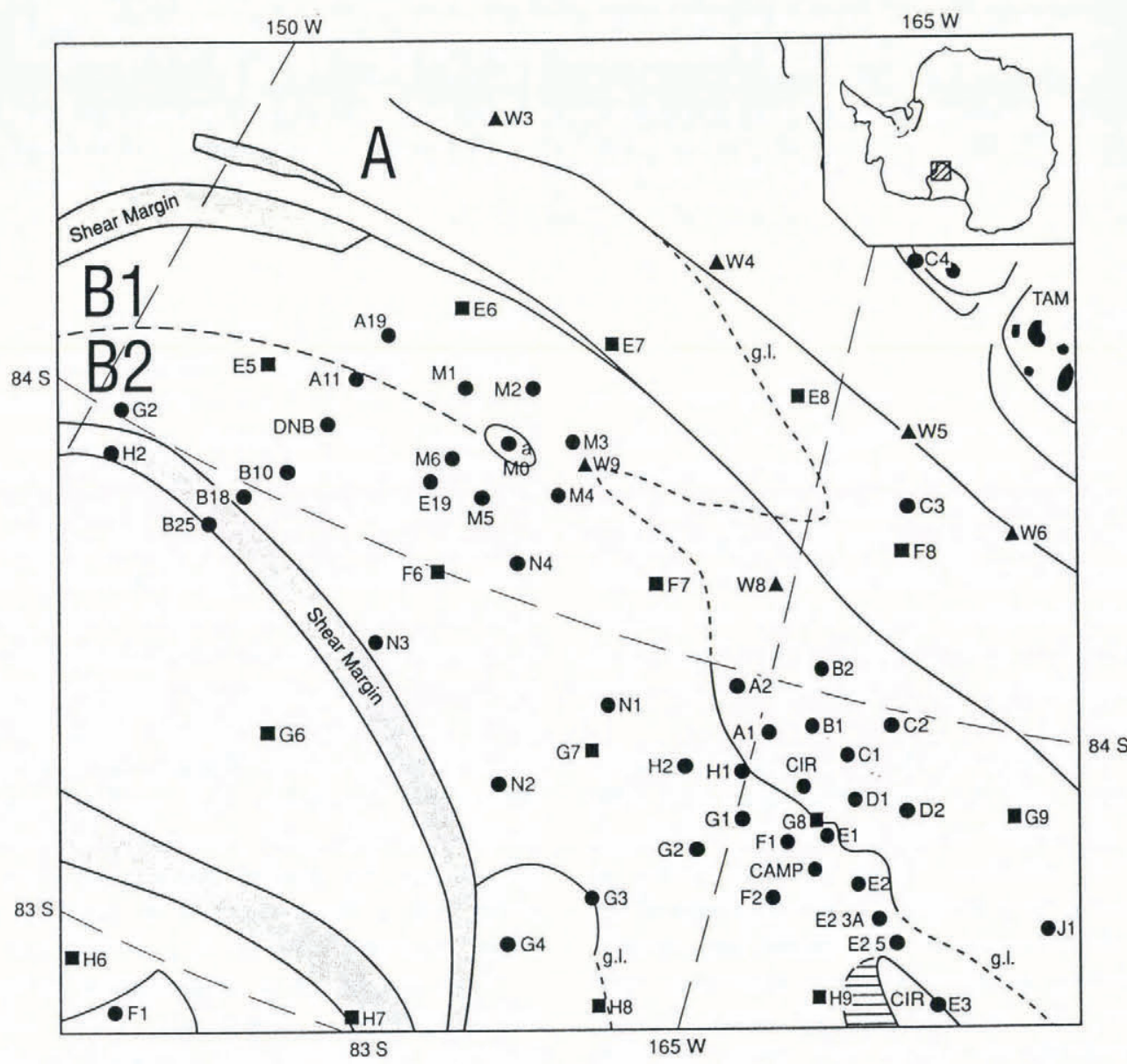

Fig. 1. Map of the study area where Ice Streams A and B enter the Ross Ice Shelf (inset shows general location). Station positions are indicated with either a solid circle or solid triangle (both Siple Coast Project stations) or a solid square (RIGGS stations). Lines indicating the lateral shear margins of the ice streams have been taken from maps prepared by $S$. Shabtaie. Grounding line (denoted "g.l.") is taken from Bindschadler (1993) (solid line) and from Shabtaie and Bentley (1988) (broken line). The boundary of Crary Ice Rise (denoted CIR) is taken from Bindschadler and others (1988) with the hachured region denoting a densely crevassed area. "TAM" denotes the Transantarctic Mountains. 
Although its appearance in a 1947 aerial photograph and its signature on airborne radar-sounding records suggest it is a grounded and stagnant ice rise, ice raft " $a$ " is moving at very close to the same velocity as the surrounding ice (Bindschadler and others, 1987).

Ice Stream A enters the Ross Ice Shelf immediately south of the ice plain. We include this region in our calculations but, as we discuss later, velocity data are too sparse to have confidence in the results.

\section{DATA AND INTERPOLATION}

The required data for calculating net mass balance are ice thickness, ice velocity, and surface and base accumulation or ablation. Each of these data sets is discussed individually below.

\section{Ice thickness}

In this region, a number of airborne-radar surveys have been conducted. Unfortunately, the two most dense surveys (Bentley and others, 1988; personal communication from Shultz) have not been reduced to useful data sets. Instead, we use those data collected by Shabtaie and Bentley (1988). They collected approximately $1190 \mathrm{~km}$ of data with ice thicknesses being measured on the
Visicorder analog output of the system every $500 \mathrm{~m}$. Figure 2 shows the network of airborne radar-sounding flights and the ice-thickness map derived from these data. As described by Shabtaie and Bentley (1988), the precision of a single ice-thickness measurement is approximately $\pm 4 \mathrm{~m}$. The onboard navigation was checked frequently by overflying surface stations of known position. They stated that this technique "allowed the mean positional accuracy (of the aircraft to be determined) to better than one kilometer along the flightlines. The resulting error in the ice-thickness gradient of $5 \times 10^{-3}$ yields an error in ice thickness of only \pm 5 meters". Thus, the total standard error is $\pm 6.4 \mathrm{~m}$. Examination of the data confirmed this - data at flight-line crossings usually agree to within $5-10 \mathrm{~m}$ but discrepancies as large as $20 \mathrm{~m}$ exist. These data were hand-contoured for this analysis with the attempt to maintain as smooth a pattern as possible. Slight differences exist between our interpretation and an earlier one published by Shabtaie and Bentley (1988, fig. 2a). For each specific difference, both interpretations are consistent with the data but our gradients are smaller.

The average thickness is about $750 \mathrm{~m}$ but there are considerable variations from this value. Station DNB is in the middle of a thick tongue of ice. This is the northern tributary (B2) of Ice Stream B. Tributary B2 thins rapidly downstream of $\mathrm{DNB}$, especially to the north, creating a strong thickness gradient of thinner ice toward

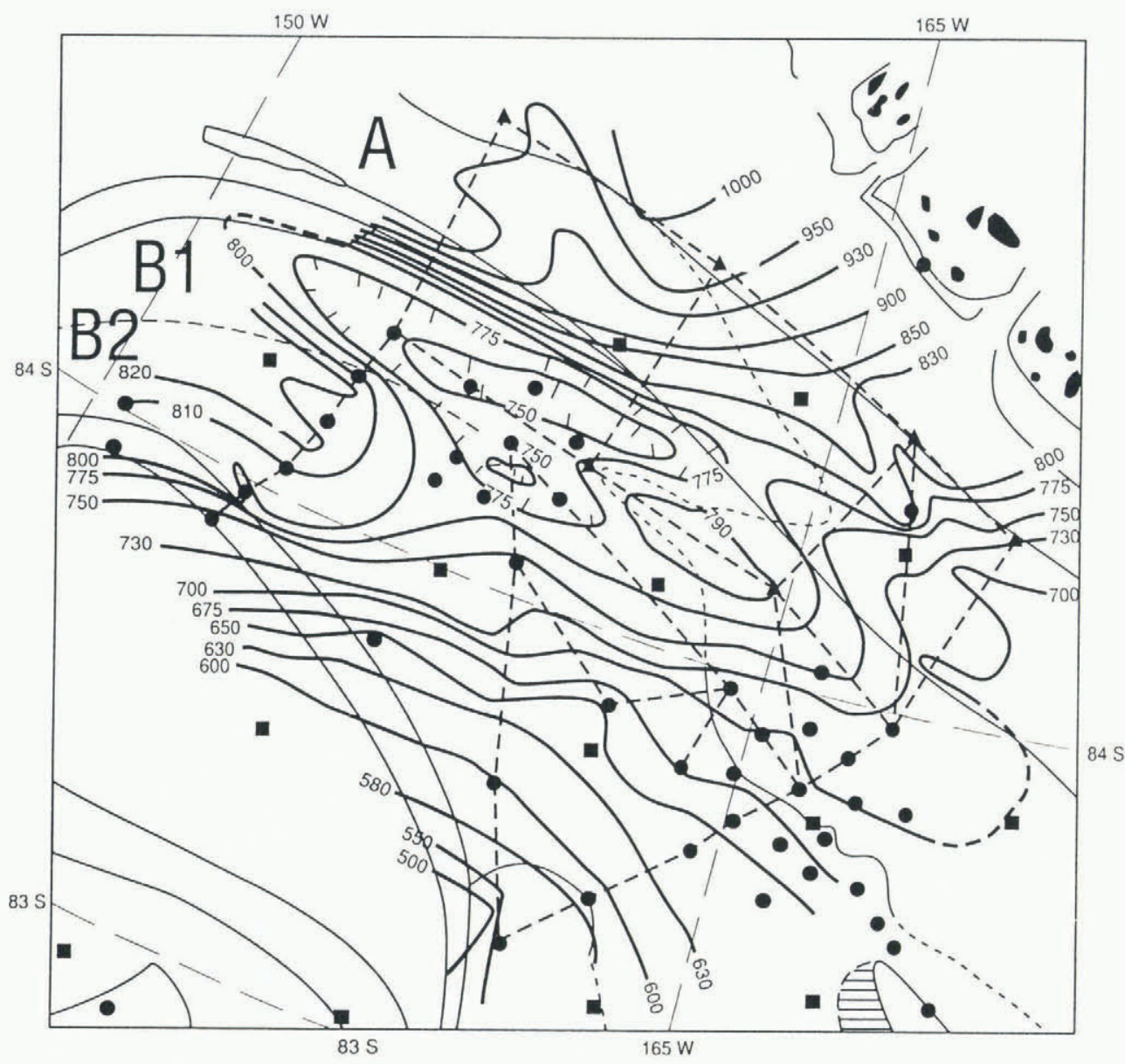

Fig. 2. Map of ice thickness. Contour interval is variable. Dashed lines connecting stations indicate airborne-radar flight lines along which ice-thickness data were collected. Between stations N4, N1, A2 and H2, the radar recordings were collected by a ground-based system. Solid circles, triangles and squares indicate stations labeled in Figure 1. 
the north-northwest. This gradient continues across most of the ice plain and the adjacent area of Ice Stream A. Two important deviations from this trend occur in Ice Stream's southern tributary (B1) where there is a broad area of thinner ice including stations M0, M1 and M2 downstream of station A19, and a region of thicker ice just downstream of this thin area, towards station W8. The connection between the thinner ice and ice raft " $a$ " is unclear. Surface-elevation data establish that the thinner ice is due to an elevated bed rather than a depressed surface (Shabtaie and Bentley, 1988, fig. 4d).

\section{Ice velocity}

Ice velocity was measured at 22 locations by repeated stake positions determined by Magnavox MX1502 geoceivers (Bindschadler and others, 1988). The positions of these data and the hand-contoured map of the velocity magnitudes (prepared by E. Roberts) are shown in Figure 3. The values are included in Table 1. Errors in individual speed measurements average $\pm 9 \mathrm{~m} \mathrm{a}^{-1}$; however, ice-speed measurements are far less dense than icethickness measurements. Surface strain rates were measured at most of the velocity stations but the values represent the local strain field averaged over distances of approximately $2 \mathrm{~km}$ (or three ice thicknesses) (Bindschadler and others, 1987). Thus, the strain rates on this grounded ice cannot be used reliably to interpolate velocities across the larger distances between stations as was done on the floating ice shelf by Thomas and others (1984). Fortunately, the large-scale gradients were calculated to be very small so the large-scale velocity field is expected to be smooth (Bindschadler and others, 1987).

As with the ice-thickness map, the contouring of the speed data attempted to minimize spatial gradients. It is consistent with each data point but only measurements made during the years $1983-86$ are used. If the three speeds measured in the $1970 \mathrm{~s}$ are plotted $\left(530 \mathrm{~m} \mathrm{a}^{-1}\right.$ at station F7, $384 \mathrm{~m} \mathrm{a}^{-1}$ at station $\mathrm{G} 8$ and $348 \mathrm{~m} \mathrm{a}^{-1}$ at station H9), it becomes clear that these do not match the pattern of Figure 3. This confirms the report of Stephenson and Bindschadler (1988) that a significant temporal deceleration occurred between these two periods of measurements.

The pattern of ice speed shown in Figure 3 illustrates significant spatial deceleration as the ice of Ice Stream B enters the ice plain. Within the ice plain, there is a general gradient of decreasing speed toward the north-northwest, similar to the gradient of decreasing ice thickness (see Fig. 2 ). The curvature of the $480 \mathrm{~m} \mathrm{a}^{-1}$ contour between stations A19 and M0 is a result of a slightly lower speed measured at station M0 located atop ice raft " $a$ ". The speed gradients across the ice exiting the ice plain between Crary Ice Rise and the northern edge of Ice Stream B demonstrate the effect of lateral shear associated

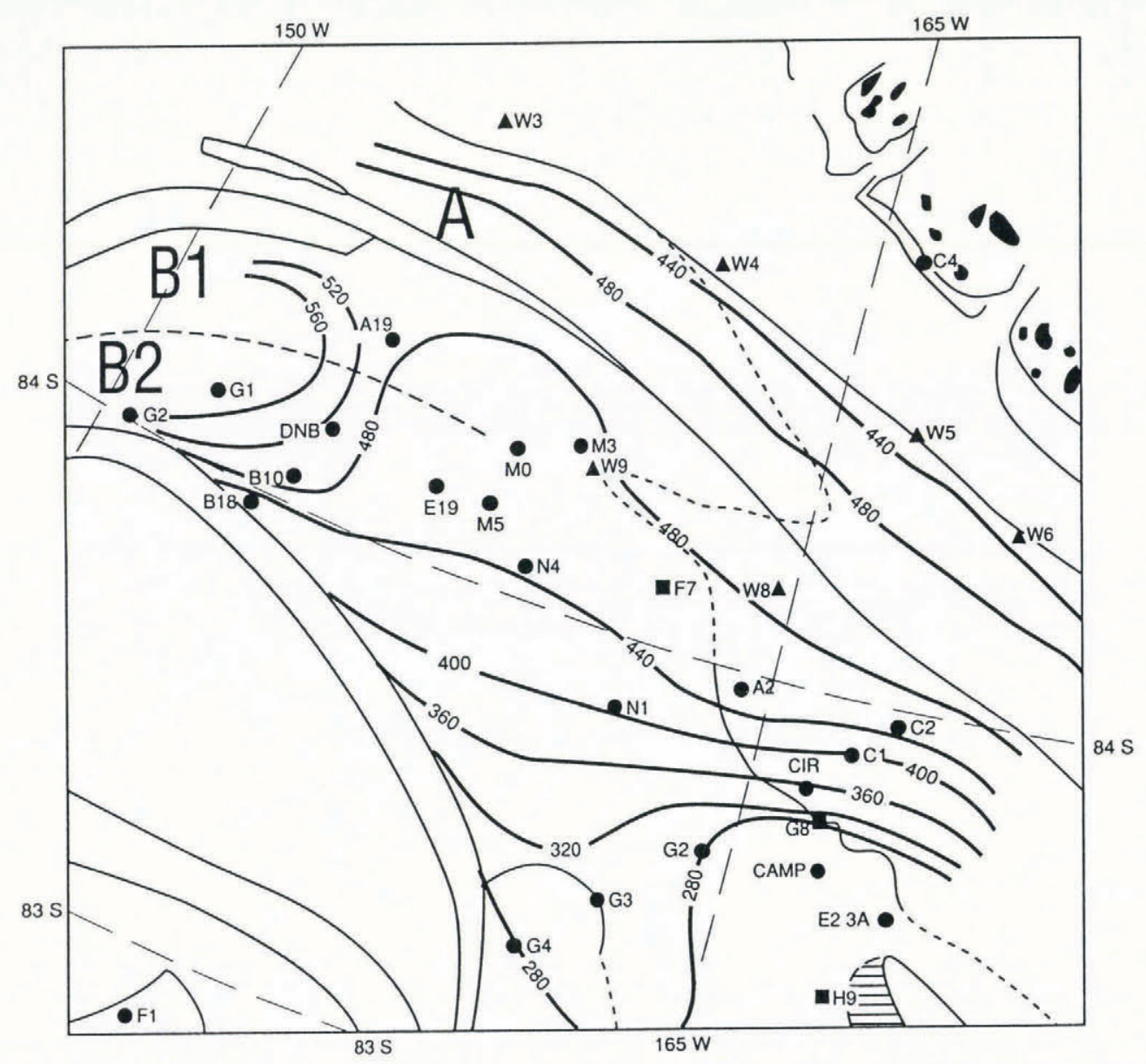

Fig. 3. Map of ice velocity. Contour interval is $40 \mathrm{~m} \mathrm{a}^{-1}$. Only those stations where velocity data were collected are shown (cf. Table 1). The three RIGGS stations (F7, G8 and H9; solid squares) were not used in the interpolation of velocity field for the reasons discussed in the text. 
Table 1. Ice plain B field data used to compile the contour maps in Figures 2-5. Values in parentheses are interpolated from data at surrounding stations. An asterisk indicates that accumulation rate was determined by $\beta$ analysis of core samples as opposed to measuring exposed stake heights. RIGGS station data are from Thomas and others (1984)

\begin{tabular}{|c|c|c|c|c|c|c|c|}
\hline \multirow[t]{3}{*}{ Station } & \multicolumn{3}{|c|}{ Accumulation rate } & \multicolumn{4}{|c|}{ Velocity } \\
\hline & \multirow{2}{*}{\multicolumn{2}{|c|}{$\begin{array}{c}\text { Ice equivalent } \\
\mathrm{m}\end{array}$}} & \multirow[t]{2}{*}{ Error } & \multirow{2}{*}{$\begin{array}{l}\text { Speed } \\
\mathrm{m} \mathrm{a}^{-1}\end{array}$} & \multirow[t]{2}{*}{ Error } & \multirow{2}{*}{$\begin{array}{c}\text { Azimuth } \\
\text { deg }\end{array}$} & \multirow[t]{2}{*}{ Error } \\
\hline & & & & & & & \\
\hline \multirow[t]{21}{*}{ (DNB) } & A11 & 0.19 & 0.01 & & & & \\
\hline & $\begin{array}{l}\text { A19 } \\
\text { B10 }\end{array}$ & & & 487 & 6 & 270.6 & 0.7 \\
\hline & & & & $\begin{array}{l}(485.6) \\
426\end{array}$ & $(0.3)$ & (273.1) & (1) \\
\hline & $\begin{array}{l}\text { B18 } \\
\text { B25 }\end{array}$ & 0.05 & 0.01 & 426 & 6 & 279.1 & 0.8 \\
\hline & $\mathrm{C} 4$ & 0.18 & 0.05 & 75 & 18 & 25 & 13 \\
\hline & DNB & 0.11 & 0.01 & 517 & 5 & 269.5 & 0.5 \\
\hline & E19 & & & 465 & 8 & 279 & 1 \\
\hline & G1 & & & 534 & 12 & 269 & 1 \\
\hline & G2 & 0.06 & 0.02 & 551 & 7 & 259.9 & 0.7 \\
\hline & M0 & 0.09 & 0.01 & 471 & 6 & 285 & 1 \\
\hline & M3 & 0.10 & 0.04 & 470 & 7 & 285 & 0.5 \\
\hline & M4 & 0.12 & 0.05 & & & & \\
\hline & M5 & 0.08 & 0.01 & & & & \\
\hline & M6 & 0.10 & 0.02 & & & & \\
\hline & $\mathrm{N} 4$ & & & 450 & 7 & 288 & 0.5 \\
\hline & W3 & & & 39 & 9 & & \\
\hline & W4 & & & 214 & 7 & 288 & 2 \\
\hline & W5 & & & 411 & 8 & 296 & 1 \\
\hline & W6 & & & 419 & 11 & 297 & 1 \\
\hline & W8 & & & 486 & 7 & 297 & 1 \\
\hline & W9 & & & 468 & 6 & 287 & 1 \\
\hline \multirow{16}{*}{ (CRARY) } & $\mathrm{Al}$ & 0.21 & 0.05 & & & & \\
\hline & $\mathrm{A} 2$ & 0.17 & 0.05 & 459 & 4 & 300 & 0.3 \\
\hline & B1 & 0.21 & 0.02 & & & & \\
\hline & B2 & 0.30 & 0.05 & & & & \\
\hline & $\begin{array}{l}\mathrm{C} 1 \\
\mathrm{C} 2\end{array}$ & $\begin{array}{l}0.30 \\
0.20\end{array}$ & $\begin{array}{l}0.02 \\
0.04\end{array}$ & & & & \\
\hline & C3 & 0.17 & 0.05 & 432 & 5 & 298 & 0.2 \\
\hline & CAMP & & & 369 & 8 & 304 & 1 \\
\hline & CIR & & & 247 & 5 & 319 & 1 \\
\hline & $\mathrm{E} 2.3 \mathrm{~A}$ & & & 171 & 7 & 312 & 2 \\
\hline & G1 & 0.22 & 0.05 & & & & \\
\hline & G2 & 0.21 & 0.04 & 283 & 7 & 326 & 1 \\
\hline & G3 & 0.07 & 0.02 & 312 & 10 & 338 & 2 \\
\hline & G4 & 0.07 & 0.06 & 264 & 14 & 342 & 3 \\
\hline & $\mathrm{Hl}$ & 0.23 & 0.02 & & & & \\
\hline & $\mathrm{H} 2$ & 0.20 & 0.01 & & & & \\
\hline & $\mathrm{Nl}$ & & & 402 & 4 & 305 & 0.3 \\
\hline \multirow[t]{7}{*}{ (RIGGS) } & E6 & $0.12^{*}$ & & & & & \\
\hline & E7 & $0.14^{*}$ & & & & & \\
\hline & E8 & $0.18^{*}$ & & & & & \\
\hline & $\mathrm{F} 6$ & $0.06^{*}$ & & & & & \\
\hline & $\begin{array}{l}\text { F7 } \\
\text { F8 }\end{array}$ & $\begin{array}{l}0.12^{*} \\
0.20^{*}\end{array}$ & & 530 & 15 & 295.9 & \\
\hline & G8 & $0.11^{*}$ & & 384 & 15 & 306.0 & \\
\hline & H9 & & & 348 & 15 & 316 & \\
\hline
\end{tabular}


with the ice flowing past those two boundaries. Ice passing to the south of Crary Ice Rise experiences even greater shear. The existence of shear in these regions is confirmed by strain-rate measurements on the floating ice (Bindschadler and others, 1988, fig. 4).

In the net mass-balance calculation, the vertical variation of horizontal velocity must be taken into acount. Bindschadler and others (1987) have shown that the average basal shear stress on this ice plain is only 0.004 bar. A basal stress this low would not cause any significant vertical variation in the velocity profile. Thus, we use surface velocities to represent the velocity through the entire ice thickness.

The directional component of ice velocity was also collected at each measurement site (Bindschadler and others, 1988; Table 1). Figure 4 shows the handcontoured map of velocity azimuth, including some representative vectors. The increasing values downstream convey the clockwise rotation experienced by the ice as it traverses the ice plain. Across-flow gradients in the azimuth signify convergence or divergence of the ice. The shaded areas of Figure 4 denote a strongly divergent region of tributary B2, where it enters the ice plain, and isolated areas of convergence. Within the northern shear margin of Ice Stream B, the ice must turn sharply as it enters the main ice-stream flow. Because this effect proved difficult to model accurately, our calculations were not extended into this boundary region.

\section{Accumulation rate}

Surface-accumulation data used a combination of firncore analysis from both the 1970s and 1980s, and stake measurements with a 1 or 2 year interval (Thomas and others, 1984; Bindschadler and others, 1988; Table 1). Because various methods were used for collecting the data, the collection represents accumulation averaged over a range of time intervals. This mixing is unavoidable, given the paucity of data.

Figure 5 shows the data used and the computerinterpolated contours calculated assuming equal weighting of all data. This figure fails to show the general increase in accumulation southward towards the Transantarctic Mountains, as noted by others (Crary and others, 1962; Clausen and others, 1979). Instead, the main feature is a region of increased accumulation upstream of Crary Ice Rise. All of the values in this region of higher accumulation are stake measurements over a 2 year interval and may represent a short-lived ephemeral condition. We estimate that the broad-scale uncertainty in the accumulation data is $\pm 0.05 \mathrm{~m} \mathrm{a}^{-1}$ (ice equivalent) while the error at any particular point might be as much as twice this value due to small-scale variability (Whillans and Bindschadler, 1988). In any event, the values of accumulation rate are small and neither they nor their spatial variation significantly alter

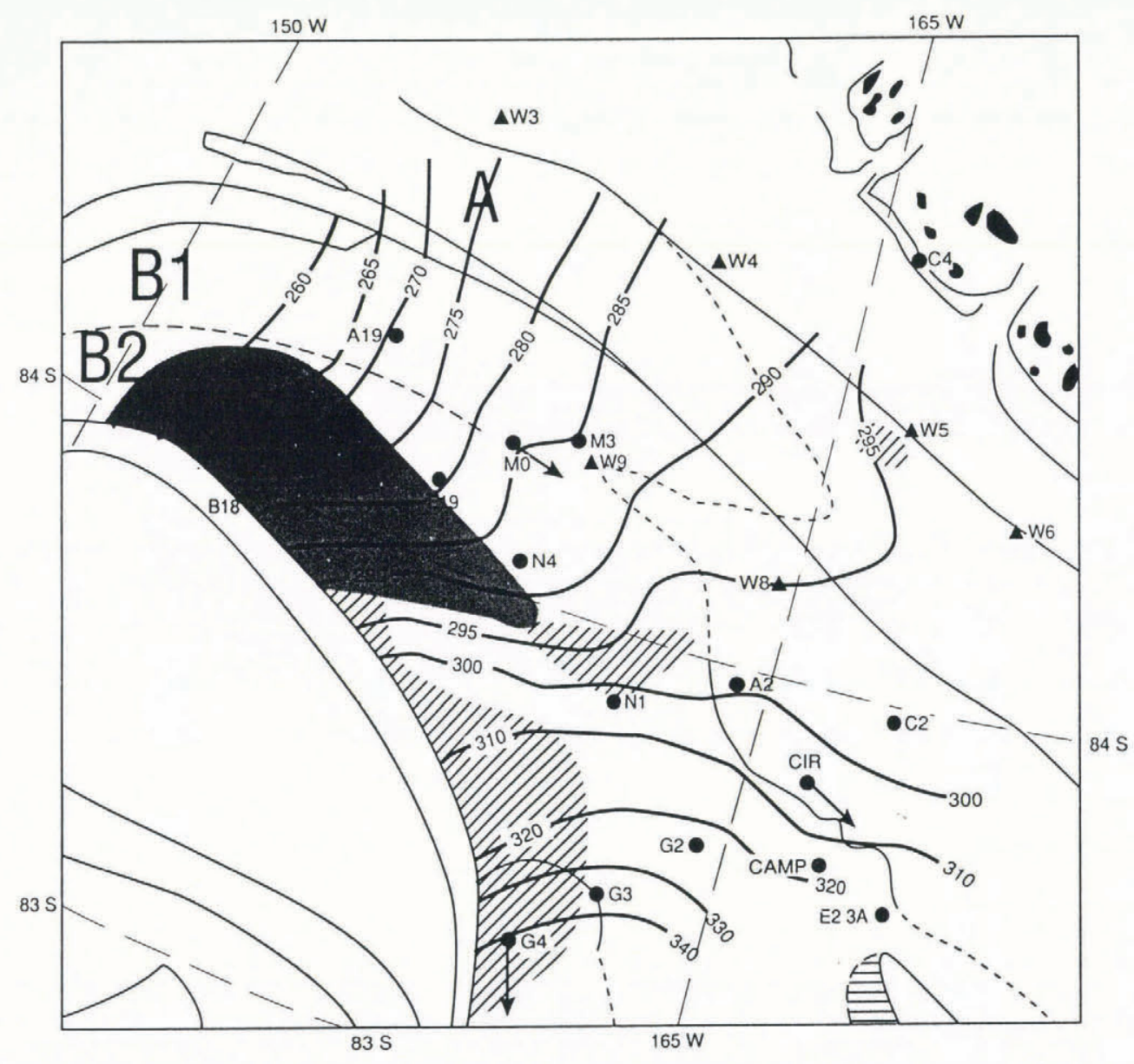

Fig. 4. Map of velocity azimuth (relative to true north). Contour interval is 5 deg. Only those stations where azimuth data were collected are shown ( $c f$. Table 1). Representative vectors are included to indicate direction of flow. Divergence exceeds $0.25 \mathrm{deg} \mathrm{km}^{-1}$ in the shaded area. Hachured areas exhibit convergence. 


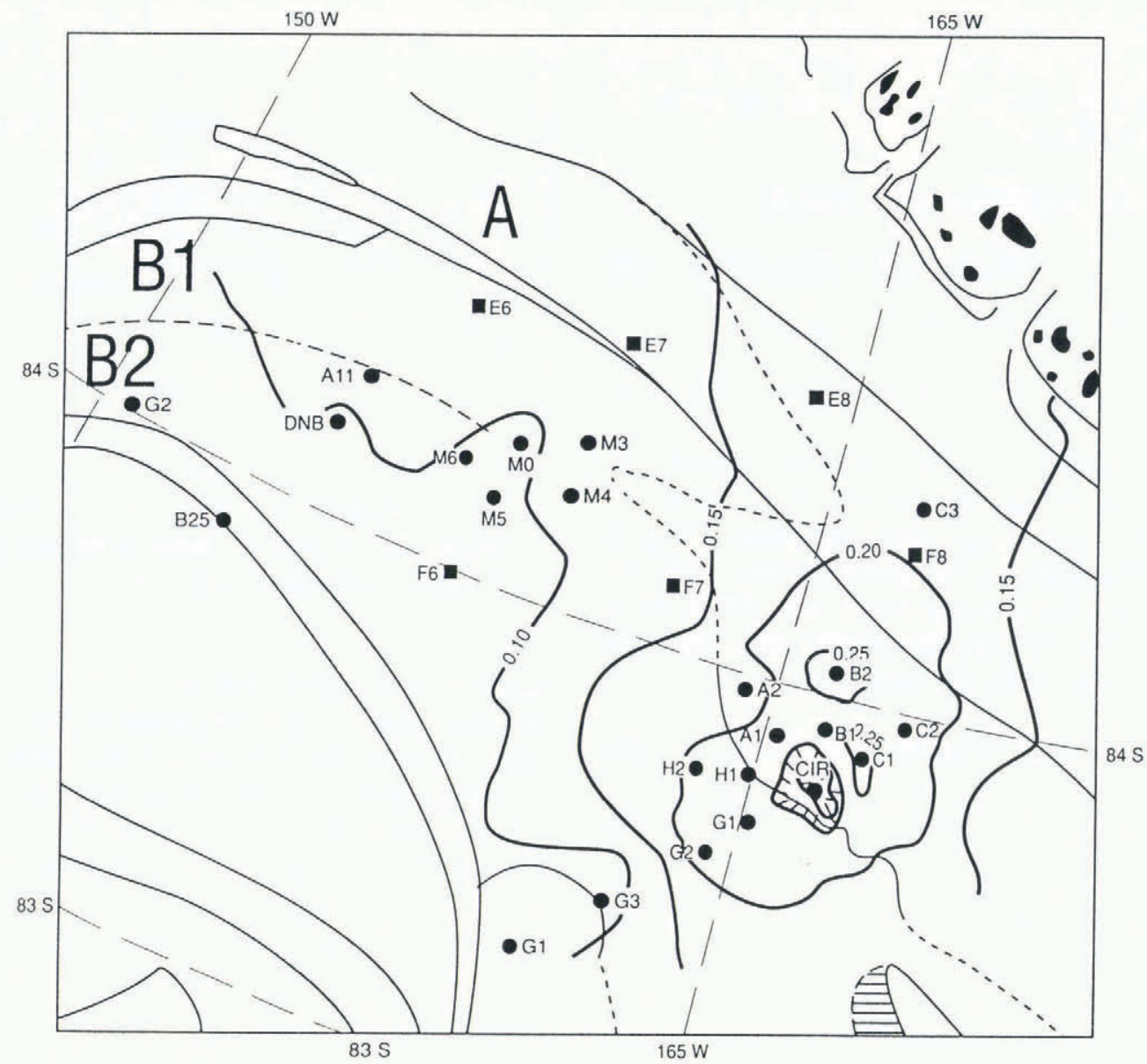

Fig. 5. Map of accumulation rate. Stations where accumulation rate was measured are included (cf. Table 1). Contour interval is $0.05 \mathrm{ma}^{-1}$ (ice equivalent).

the major pattern of computed net mass balance discussed below.

No attempt is made to quantify mass exchange at the base of the ice. While this process is believed to be insignificant at the base of the grounded ice plain, considerable basal melting could occur beneath the floating ice shelf, particularly in the vicinity of the grounding line of the thicker ice tongues (Robin, 1979). We shall return to this point in the discussion of our calculations in the ice-shelf areas.

\section{Geographical information system}

All the above data fields can be considered as separate data "levels" of a geographic information system (GIS). A GIS consists of multiple-data sets (or levels) all referenced to the same geographic grid. The advantage of this concept is that it facilitates the intercomparison of any of the data levels. All algebraic combinations of different data levels generate new data levels that can be compared with any other levels. Examples of other data levels are satellite imagery, aerial photography, flight lines and/or field-traverse data.

For our GIS system, we chose a $1 \mathrm{~km}$ spacing in polar stereographic projection and an Earth radius of $6356.75 \mathrm{~km}$. The map of each parameter-ice thickness, velocity (both speed and azimuth) and accumulation rate-was digitized using ARCINFO software. Interpolation to the GIS grid was performed using a routine that searches for data points with a user-defined distribution around each search location. The userdefined parameters included a search radius and the minimum and maximum number of data points in each octant surrounding the search location. Different values of parameters were tried until the result gave a good balance between the presence of grid "holes" (locations where no interpolated value was returned) and smoothness of the contours.

\section{GALGULATION OF NET MASS BALANGE}

The net mass balance for any grid cell is calculated by summing the normal component of mass flux across each of the four vertical faces and adding the mass contributions from the top and bottom surfaces:

$$
N=\rho\left[\sum_{\substack{\text { vertical } \\ \text { faces }}} Q_{n}+(A+B) W_{x} W_{y}\right]
$$

where $N$ is the net mass balance, $\rho$ is the density of ice $\left(917 \mathrm{~kg} \mathrm{~m}^{-3}\right), Q_{n}$ are the volume fluxes across each of the four vertical faces, $W_{x}$ and $W_{y}$ are the widths in the $x$ and $y$-directions, $A$ is surface accumulation and $B$ is basal accumulation. Figure 6 portrays the grid scheme used. Ice-thickness and velocity values are specified at each grid 
point, while the vertical faces of each grid cell occur between grid points. Thus midpoint approximations are used to calculate the mass flux from the grids of ice thickness and ice velocity:

$$
\begin{gathered}
Q_{n}\left(i \pm \frac{1}{2}, j\right)=\mp \frac{1}{4}[H(i+1, j)+H(i, j)] \\
\cdot\left[U_{x}(i+1, j)+U_{x}(i, j)\right] W_{y} \\
Q_{n}\left(i, j \pm \frac{1}{2}\right)=\mp \frac{1}{4}[H(i, j \pm 1)+H(i, j)] \\
\cdot\left[U_{y}(i, j \pm 1)+U_{y}(i, j)\right] W_{x}
\end{gathered}
$$

where $i$ and $j$ are grid coordinates, $H$ is the ice thickness, and $U_{x}$ and $U_{y}$ are the components of velocity in the $x$ (or $i$-) direction and in the $y$ - (or $j$-) direction. The grid used in this analysis aligns the positive $y$-axis with the $180^{\circ}$ meridian and the positive $x$-axis with $90^{\circ} \mathrm{E}$. With this orientation, the velocity components are calculated from the velocity vector by the formulas:

$$
\begin{aligned}
& U_{x}(i, j)=|\vec{U}(i, j)| \sin [\theta(i, j)+\phi(i, j)] \\
& U_{y}(i, j)=|\vec{U}(i, j)| \cos [\theta(i, j)+\phi(i, j)]
\end{aligned}
$$

where $\vec{U}$ is the velocity vector, $\theta$ is the velocity azimuth and $\phi$ is the longitude of gridpoint $(i, j)$ (west longitudes are negative).

Throughout this paper we will express net mass balance in terms of ice-equivalent thickening or thinning by the following formula:

$$
\frac{\mathrm{d} H}{\mathrm{~d} t}=\frac{N}{\left(W_{x} W_{y} \rho\right)} .
$$

Substituting Equations (1) through (3) into Equation (6) yields the equation used to calculate $\mathrm{d} H / \mathrm{d} t$ :

$$
\begin{aligned}
& \frac{\mathrm{d} H}{\mathrm{~d} t}=\frac{1}{4 W_{x}}\{ {[H(i-1, j)+H(i, j)] } \\
& \cdot\left[U_{x}(i-1, j)+U_{x}(i, j)\right] \\
&-[H(i+1, j)+H(i, j)] \\
&\left.\cdot\left[U_{x}(i+1, j)+U_{x}(i, j)\right]\right\} \\
&+\frac{1}{4 W_{y}}\{[H(i, j-1)+H(i, j)] \\
& \cdot\left[U_{y}(i, j-1)+U_{y}(i, j)\right] \\
&-[H(i, j+1)+H(i, j)] \\
&\left.\cdot\left[U_{y}(i, j+1)+U_{y}(i, j)\right]\right\}+(A+B) .
\end{aligned}
$$

The terms of Equation (7) represent the gradients of flux in the two orthogonal directions, plus the surface and base accumulation.

As mentioned earlier, surface velocities are used for the depth-averaged values and basal accumulation, or melting is assumed negligible for the ice plain and ignored under the ice shelf (i.e. $B=0$ ).

When Equation (7) was applied to the data, the result was very noisy and displayed artifacts caused by the digitization and interpolation processes. The large

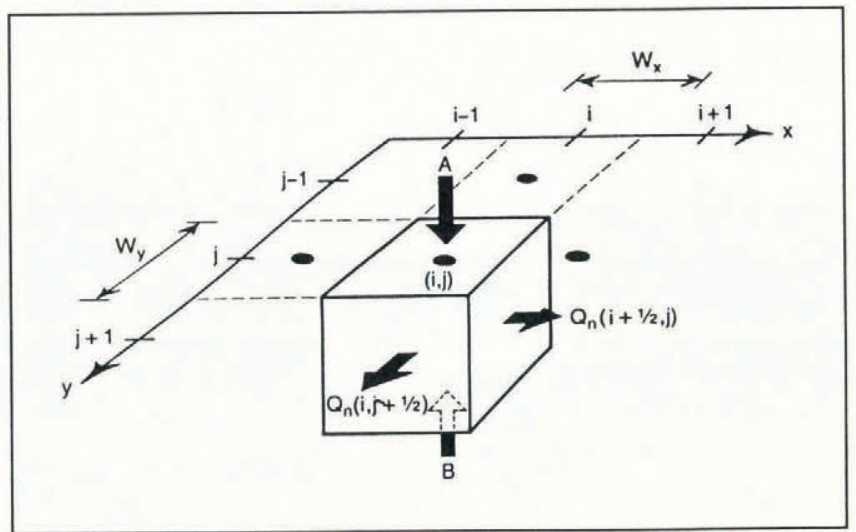

Fig. 6. Diagram of scheme used to compute net mass balance for a grid cell centered at grid point $(i, j)$. Parameters are defined in the text.

variation was due to the fact that the uncertainties in the data were large compared to the true gradients expected over the relatively small grid interval. The standard errors of ice thickness, speed and accumulation rate discussed above were $6.4 \mathrm{~m}, 9 \mathrm{~m} \mathrm{a}^{-1}$ and $0.1 \mathrm{~m} \mathrm{a}^{-1}$, respectively. Propagation of these errors through Equation (7), using a mean ice thickness of $800 \mathrm{~m}$, a mean ice speed of $440 \mathrm{ma}^{-1}$ and a $1 \mathrm{~km}$ grid spacing, yields a standard error of the net mass balance of $\pm 6.7 \mathrm{~m} \mathrm{a}^{-1}$.

This error is reduced significantly by applying a $31 \mathrm{~km} \times 31 \mathrm{~km}$ running-average filter to the calculated net mass-balance field. Figure 7 shows the result after this averaging. The area shown in Figure 7 represents only those pixels that had every parameter required by Equation (7). As a result of the large number of points used in the averaging, the standard error is reduced to $0.22 \mathrm{~m} \mathrm{a}^{-1}$ over the majority of the region. Within $15 \mathrm{~km}$ of the edge of the data, the algorithm averages fewer points and errors rise rapidly as the edge is approached. Figure 7 shows many features in the pattern of net mass balance that are well above this error, indicating that the ice plain is a region experiencing considerable dynamic change.

\section{PATTERN OF NET MASS BALANCE}

Negative net mass balance (i.e. thinning ice) could be caused separately by along-flow gradients of either increasing ice thickness or of increasing ice speed, divergence in the flow direction, or surface or basal ablation. Positive net mass balance would be caused by any of the opposite effects. In our analysis of the calculated pattern of net mass balance shown in Figure 7, we identify the following major features:

1. Thinning along the northern half of the ice plain.

2. Thickening over the southern half of the ice plain, changing to thinning within the upstream embayment of the ice shelf.

3. Thickening at the downstream end of the ice plain.

4. Thickening in the region fed by Ice Stream A.

Other features at or near the edge should be ignored because of the larger errors there. We discuss each of these major features below and identify both the specific causes 


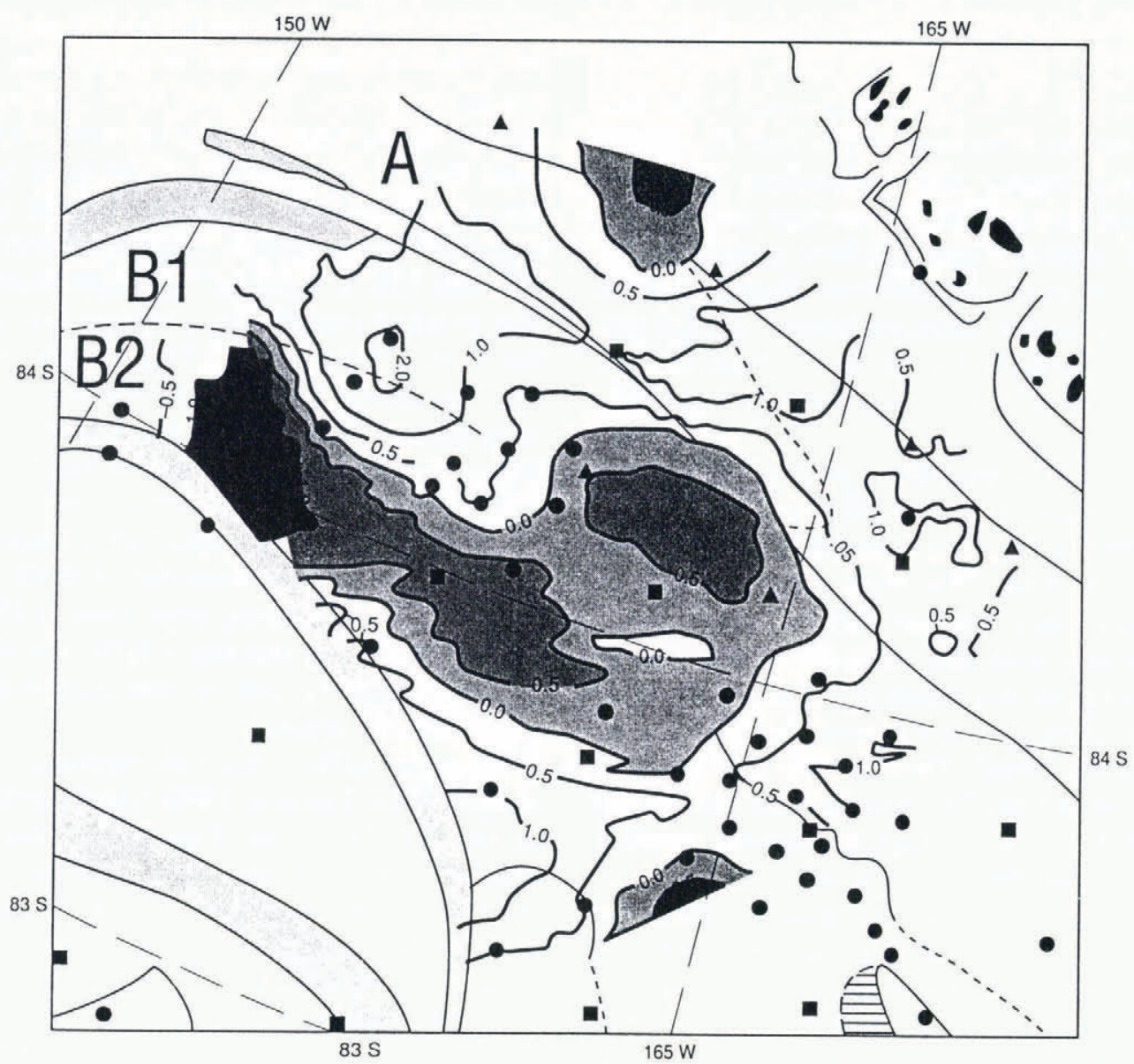

Fig. 7. Calculated net mass balance. Contour interval is $0.5 \mathrm{ma}^{-1}$. Station names can be found in Figure 1 to help locate major features of the net mass-balance pattern discussed in the text.

of each feature and review the original field data to assess the reliability of our calculated result. Because the magnitude of the features discussed is much greater than the accumulation rate, the cause of each region's imbalance is due to gradients of either velocity or thickness and not the acccumulation rate.

The band of thinning that occurs over the northern half of the ice plain is most intense north of station DNB and decreases further downstream. This region is fed by ice from B2 (the north tributary of Ice Stream B). This thinning is clearly not the result of gradients in either the ice thickness or speed. Figures 2 and 3 indicate negative downstream gradients of these two parameters which, by themselves, would result in thickening not thinning. Rather, the calculated negative net mass balance is a result of the strong flow divergence experienced as B2 enters the ice plain which more than compensates for the effects of the thickness and speed gradients (cf. Fig. 4). This strong divergence persists downstream and is responsible for the downstream extension of the thinning region. Near the downstream end of the ice plain, the ice flow becomes convergent, associated with the downstream presence of Crary Ice Rise, and local values of net mass balance rise to positive values (i.e. thickening). This pattern of net mass balance on tributary B2 is reliable, particularly in the vicinity of DNB where field data are dense. As an additional check on the speed map, the measured surface strain rates along the transverse profile extending from DNB northward to the shear margin agree very well with the gradients from the speed map.
Strain rates farther downstream on the ice plain also confirm the persistence of flow divergence (Bindschadler and others, 1987).

South of DNB, the ice plain is fed by ice from B1, the south tributary of Ice Stream B. Figure 7 shows that thickening is calculated for this area. As within B2, the competing parameters are divergence, ice-thickness gradient and speed gradient, but in this area the divergence is not sufficiently large to overcompensate for the negative speed and thickness gradients. It is important to note, however, that few velocity data are available in this area. The contours in Figure 3 were drawn to represent plug flow across Ice Stream B. Satellite images show no major obstacle impeding flow in this area (Bindschadler, 1993). Any deviation from plug flow would only serve to redistribute and probably amplify the thickening. The only exception to this is that, if the speed of the ice entering the study area upstream of station Al9 is lower, then the calculated thickening rates upstream of A19 would be reduced. The large area of thinner ice located in the vicinity of stations M0, M1 and M2 creates a strong negative gradient of thickness upstream of station W9 (cf. Fig. 2), and it is this gradient which is mainly responsible for the calculated positive net mass balance upstream of this feature. Because this thin area was crossed many times by the airborne radar, it is a reliable feature.

Continuing in tributary $\mathrm{Bl}$, downstream of this thickening area the net mass-balance trend reverses to strong thinning. The transition almost coincides with the 
position of the grounding line at a very large embayment (cf. Fig. 1). The grounding line was determined independently by analysis of airborne radar-reflection strengths (Shabtaie and Bentley, 1987) and by observations of strand cracks during surface traverses (Bindschadler and others, 1988). From our calculations, this thinning is a result of a strong positive gradient in the ice thickness as ice leaves the thin area discussed above and, for the same reasons discussed above, we feel this calculated result is dependable; however, basal melting (or freezing) could modify the actual net mass balance in this area.

Both the B1 and B2 tributaries experience thickening in the most downstream section of the studied area (before the profile G4-C2). Ice in this region has to flow around Crary Ice Rise. The field data of surfacehorizontal strain rates confirm lateral compression throughout this area with the exception of ice flowing directly towards the ice rise which is undergoing intense longitudinal compression (and lateral tension) (Bindschadler and others, 1988). The velocity field properly represents these dynamics. The ice-thickness field is well sampled and shows a large negative gradient trending north-northwest. Thus, this feature is also reliable.

According to the grounding-line position shown in Figure 1, most of this region is grounded and only the northern corner including station G4 and the southern side including stations $\mathrm{W} 8, \mathrm{~B} 2$ and $\mathrm{C} 2$ are floating (Bindschadler, 1993). Basal melting, therefore, might reduce the calculated thickening rates but only in the limited floating areas.

The southernmost part of the studied region corresponds to ice entering the ice shelf from Ice Stream A. It is dominated by positive net mass-balance values with the exception of a small area near the southern extreme. This small area of thinning is the result of a positive gradient in the ice thickness which is itself an artifact of the extrapolation of the ice-thickness data. Furthermore, the velocity data over the entire region occupied by ice from Ice Stream $\mathrm{A}$ are very sparse and the calculated net mass balances of this area are probably not trustworthy.

Over the entire region shown in Figure 7, the net mass balance is $0.32 \pm 0.04 \mathrm{~m} \mathrm{a}^{-1}$ (ice equivalent). Because this includes the area of Ice Stream A, where we feel our calculations are suspect, we also averaged only the Ice Stream B part of the region and calculated an average net mass balance of $0.13 \pm 0.05 \mathrm{~m} \mathrm{a}^{-1}$.

\section{COMPARISON WITH EARLIER ESTIMATES}

Net mass-balance estimates in this area have been calculated before and it is useful to compare the results. The most comprehensive previous effort was made by Shabtaie and others (1988) using the traditional "gate" approach. These authors also calculated an asymmetry between B1 and B2 on the ice plain; however, it must be noted that their calculation used the velocity at station F7 to calculate discharge exiting the ice plain at their gate "G6" (a line roughly transverse to flow at station F7). As Stephenson and Bindschadler (1988) reported, the velocity at this location had decreased by approximately $12 \%$ between 1975 and 1984 . Because all other velocities in this area used by Shabtaie were circa this more recent date, the calculations of Shabtaie and others (1988) require correction. To make these corrections, we lower the flux across their G6 gate by $12 \%$. This raises the net mass balance for the $\mathrm{Bl}$ and $\mathrm{B} 2$ parts of the ice plain between the transverse profile at DNB (their gate G5) and gate G6 (see table 1 of their publication) to $0.03 \pm$ 0.35 and $0.25 \pm 0.40 \mathrm{~m} \mathrm{a}^{-1}$ (ice equivalent), respectively. Our detailed calculations averaged over the same areas are $-0.11 \pm 0.12 \mathrm{~m} \mathrm{a}^{-1}$ for $\mathrm{B} 1$ and $-0.06 \pm 0.10 \mathrm{~m} \mathrm{a}^{-1}$ for B2. The sense of asymmetry is the same in each case (B2 more positive than B1) and the smaller standard error of this work falls entirely within the range of one standard error of the Shabtaie and others (1988) estimate.

Farther upstream, their area between gates G4 (approximately $75 \mathrm{~km}$ upstream of DNB) and G5 (DNB profile) indicated strong thickening $\left(1.85 \pm 0.36 \mathrm{~m} \mathrm{a}^{-1}\right)$ on $\mathrm{B} 1$ and strong thinning $\left(-2.28 \pm 0.52 \mathrm{~m} \mathrm{a}^{-1}\right)$ on $\mathrm{B} 2$. This matches very well our calculations of the upstream area of the ice plain.

Another earlier, but less rigorous, calculation was completed by Thomas (1976) which predicted thickening at rates of many tens of centimeters per year over this region. While these rates are much higher than our result, the source of the error can be linked to his assumption of zero lateral strain. As we have discussed, the ice-plain area is experiencing general divergence.

At the downstream end of the ice plain, our region adjoins the upstream end of a net mass-balance study completed by Bindschadler and others (1989). Their most upstream box extended from the line between stations G2 and C2 downstream to Crary Ice Rise and was calculated to be thickening at $0.76 \mathrm{~m} \mathrm{a}^{-1}$, in good agreement with our results. Additional corroboration of thickening in this region comes from a comparison of ice-thickness measurements made during the International Geophysical Year (IGY) and in 1984 that indicate thickening rates of nearly $2 \mathrm{~m} \mathrm{a}^{-1}$ in the vicinity of station $\mathrm{Cl}$ (Bindschadler, 1993).

Finally, two estimates of the net mass balance in overlapping regions southeast of Crary Ice Rise were carried out by Thomas and Bentley (1978) and Jezek and Bentley (1984). In the first case, a substantial fraction of their study area falls outside our study area and, in the second case, most of their area occurs in Ice Stream A, where we feel our results are not dependable. Added to this is the fact that both studies were made using older velocity data which, as has been discussed above, are incompatible with the velocity data used in this paper. Thus, we do not attempt any quantitative comparison of those results with results presented here.

The comparison discussed above between our results and those using a more traditional "gate" approach helps to illustrate the major advantage of the GIS-based approach. Figure 7 displays the detailed spatial pattern of net mass balance and highlights the asymmetry between tributaries B1 and B2 that is missed in the traditional approach due to the unfortunate placement of gates that encompass significant variations in the net mass balance. Similar shortcomings arose in an earlier unpublished analysis of these data by one of us (R.A.B.) that attempted to use the traditional approach with gates being chosen to coincide with the radar flight line (cf. Fig. 
2). This unpublished work produced accurate estimates of the net mass-balance value for each box defined by the radar flight lines but the configuration of the boxes was so irregular that a meaningful interpretation of the behavior of individual tributaries was impossible.

\section{DYNAMIC IMPLICATIONS}

The major features of the net mass-balance pattern of which we are most confident are those on the ice plain fed by Ice Stream B. Figure 7 provides a much clearer picture of the dynamics of change now taking place in this region than was available with earlier analyses. There is a strong asymmetry between the behaviors of tributaries B1 and B2. Tributary B2 exhibits a more consistent pattern of thinning extending throughout its entire ice plain. The calculations of Shabtaie and others (1988) show that this effect spans the lower half of Ice Stream B and not just the ice plain. Thus, it is likely that this situation will persist for some time.

The region of thinnest ice (centered on station M1) occurs on tributary $\mathrm{Bl}$ and coincides roughly with the location of greatest thickening rate. However, the ice is thin due to an elevated bed and not a depressed surface (Shabtaie and Bentley, 1988). Prolonged thickening will create an increased surface slope between this region and the thinning region downstream. Using the data presented by Bindschadler and others (1987), the surface slope will double in just over 10 years. Such a rapid increase in the driving stress is certain to produce major changes in the dynamics of this tributary.

The position of the rapid shift from thickening to thinning coincides roughly with both the embayment in the grounding line and ice raft " $a$ ". Having assumed no sub-shelf accumulation or ablation $(B=0)$, the true rates of thickness change in the floating areas may differ from those of Figure 7. However, basal melting is more likely at grounding lines and this would increase the thinning rate. The pattern of upstream thickening and downstream thinning would be expected in the neighborhood of an ice rise. Ice raft " $a$ ", although once believed to be an ice rise, is now moving but at slightly less than "full speed" (see the curvature of the $480 \mathrm{~m} \mathrm{a}^{-1}$ contour in Figure 3) and this difference contributes to the pattern of thickening and thinning portrayed in Figure 7. It is certainly possible that the thinning in the lee of ice raft "a" is responsible for the embayment in the grounding line. If ice raft " $a$ " formed at a position within the thinner ice upstream of its current location (where the bed is higher), then it only very recently has released and may still be in the last stages of acceleration.

It has been suggested that the deceleration of the ice plain noted by Stephenson and Bindschadler (1988) has been caused by the excess discharge of Ice Stream B increasing the basal shear at the base of the ice plain. Figure 7, however, shows a vast area of thinning in the vicinity of station F7, one of three stations where deceleration was inferred. Thus, at least at station F7, local thickening cannot be the cause of the deceleration. An alternative explanation is that the deceleration was caused by thickening elsewhere and longitudinal stresses were responsible for the transmission of this effect to other areas. If this hypothesis is true, the only areas where the basal shear could have increased are either the broad area upstream of Crary Ice Rise or the area upstream of ice raft " $a$ ". Because the amount of deceleration decreased with distance from Crary Ice Rise (32\% at $\mathrm{H} 9,16 \%$ at G8 and $12 \%$ at F7; cf. Fig. 1), we believe that thickening upstream of the ice rise is the likely cause of the deceleration.

\section{SUMMARY}

There are significant variations in the rates of thickness change occurring on the ice plain of Ice Stream B. Overall, the ice-plain region is thickening and there are real differences in the current behaviors of tributaries B1 and B2. On the one hand, B1 is thickening upstream of ice raft " $a$ " and thinning downstream where the grounding line makes a large upstream deviation. On the other hand, B2 is thinning in the upstream area of the ice plain and this thinning persists downstream, driven by the divergence of ice flow which more than compensates for negative downstream gradients of ice thickness and velocity. Just upstream of Crary Ice Rise, both tributaries experience thickening as they flow around the ice rise.

The discovery of this detailed spatial pattern of net mass balance was facilitated by the organization of disparate data sets into a GIS framework, where a common high-resolution grid was specified. While denser original data sets would have improved the accuracy of the calculations, spatial averaging of the interpolated data sets reduced the uncertainties to the level where significant features of the net mass-balance field could be identified. The common grid facilitated the correlation of major features of the net mass-balance field with features in the input-data fields and led to new insights into the dynamics of the ice plain of Ice Stream B.

\section{ACKNOWLEDGEMENTS}

We should like to acknowledge the considerable work by E. Roberts in the assimilation of the velocity data into the velocity field used in this paper. The manuscript was improved on the basis of comments received by $\mathrm{D}$. MacAyeal, T. Hughes, R. Thomas and an anonymous reviewer. The research was supported by the U.S. National Science Foundation under grants DPP8614407 and DPP-8946322.

\section{REFERENGES}

Alley, R. B. and I. M. Whillans. 1991. Changes in the West Antarctic ice sheet. Science, 254(5034), 959-963.

Bentley, C. R., D. D. Blankenship and G. Moline. 1988. Electromagnetic studies on the Siple Coast, 1987-1988. Antart. J. U.S., 23(5), 56-58.

Bindschadler, R. A. 1993. Siple Coast Project research of Crary Ice Rise and the mouths of Ice Streams B and C, West Antarctica: review and new perspectives. F. Glaciol., 39(133), 538-552.

Bindschadler, R. A. and T.A. Scambos. 1991. Satellite-image-derived velocity field of an Antarctic ice stream. Science, 252(5003), 242-246. 
Bindschadler, R. A., S. N. Stephenson, D. R. MacAyeal and S. Shabtaie. 1987. Ice dynarnics at the mouth of Ice Stream B, Antarctica. F. Geophys. Res., 92(B9), 8885-8894.

Bindschadler, R. A., S. N. Stephenson, E. P. Roberts, D. R. MacAyeal and D.R. Lindstrom. 1988. Data report for the Siple Coast Project. Washington, DC, National Aeronautics and Space Administration. (NASA Tech. Memo. 100708.)

Bindschadler, R.A., E.P. Roberts and D.R. MacAyeal. 1989. Distribution of net mass balance in vicinity of Crary Ice Rise, Antarctica. F. Glaciol., 35(121), 370-377.

Clausen, H. B., W. Dansgaard, J. O. Nielsen and J.W. Clough. 1979. Surface accumulation on Ross Ice Shelf. Antarct. J. U.S., 14(5), 6872.

Crary, A.P., E. S. Robinson, H.F. Bennett and W.W. Boyd. 1962. Glaciological studies of the Ross Ice Shelf, Antarctica, 1957-1960. IGY Glaciol. Rep. Ser. 6.

Jezek, K.C. and C. R. Bentley. 1984. A reconsideration of the mass balance of a portion of the Ross Ice Shelf, Antarctica. 7. Glaciol., 30(106), 381-384.

Robin, G. de Q 1979. Formation, flow, and disintegration of ice shelves. 7. Glaciol., 24(90), 259-271.

Shabtaie, S. and C. R. Bentley. 1987. West Antarctic ice streams draining into the Ross Ice Shelf: configuration and mass balance. $\mathcal{F}$. Geophys. Res., 92(B2), 1311-1336.
Shabtaie, S. and C.R. Bentley. 1988. Ice-thickness map of the West Antarctic ice streams by radar sounding. Ann. Glaciol., 11, 126-136.

Shabtaie, S., C. R. Bentley, R.A. Bindschadler and D. R. MacAyeal. 1988. Mass-balance studies of Ice Streams A, B, and C, West Antarctica, and possible surging behavior of Ice Stream B. Ann. Glaciol., 11, 137-149.

Stephenson, S.N. and R.A. Bindschadler. 1988. Observed velocity fluctuations on a major Antarctic ice stream. Nature, 334(6184), 695697.

Thomas, R. H. 1976. Thickening of the Ross Ice Shelf and equilibrium state of the West Antarctic ice sheet. Nature, 259(5540), 180-183.

Thomas, R.H. and C.R. Bentley. 1978. The equilibrium state of the eastern half of the Ross Ice Shelf. F. Glaciol., 20(84), 509-518.

Thomas, R. H., D. R. MacAyeal, D. H. Eilers and D. R. Gaylord. 1984. Glaciological studies on the Ross Ice Shelf, Antarctica, 1973-1978 Antarct. Res. Ser., 42, 21-53.

Whillans, I.M. and R.A. Bindschadler. 1988. Mass balance of Ice Stream B, West Antarctica. Ann. Glaciol., 11, 187-193.

Zwally, H.J. 1977. Microwave emissivity and accumul-ation rate of polar firn. F. Glaciol., 18(79), 195-215.

The accuracy of references in the text and in this list is the responsibility of the authors, to whom queries should be addressed. 